\section{CONGENITAL DIAPHRAGMATIC HERNIA: 15 YEAR-EXPERIENCE IN A PEDIATRIC INTENSIVE CARE UNIT}

\author{
J. Pimenta ${ }^{1}$, P. Silva ${ }^{2}$, C. Pinto ${ }^{1}$, F. Neves ${ }^{1}$ \\ ${ }^{1}$ PICU, ${ }^{2}$ Cardiology, Hospital Pediatrico de \\ Coimbra, Coimbra, Portugal
}

Background and aims: congenital diaphragmatic hernia $(\mathrm{CDH})$ is a rare malformation with a high mortality rate. Prenatal diagnosis is essential in defining the optimal perinatal therapeutic strategy. All cases of Portugal's Central Region have been referred to PICU of Coimbra's Pediatric Hospital $(\mathrm{CPH})$. The aims were to determine the incidence of $\mathrm{CDH}$, to characterize the newborns (NB) with $\mathrm{CDH}$ admitted to the PICU, to evaluate the mortality and its evolutionary pattern.

Methods: a retrospective, study analysis made up of children with $\mathrm{CDH}$ was undertaken in a 15 year period. Based on the admission' year, two groups were formed: group A (1995-2001) and group B (2002-2009), where the newborns' characteristics, therapeutic strategies, prognostic factors and mortality were compared.

Results: the mean annual incidence was 2.2 per 10.000 live-newborn. Of the $60 \mathrm{NB}$ admitted to the PICU-CPH, $48.7 \%$ were prenatally diagnosed, $38 \%$ had associated malformations and $23.3 \%$ had a right-sided defect. $71.7 \%$ were born in perinatal tertiary referral centre. Regarding prognostic factors, newborns' characteristics and underlying therapeutic strategies, no statistically significant differences were observed between the two study groups. Prenatal diagnosis was made in $37.5 \%$ in the group $A$ and $52.8 \%$ in the group $B$ cases $(p=0.369)$. The mortality in group $A(29 \%)$ was significantly higher than in group $B(5 \% ; p=0.032)$.

Conclusions: a significant decrease in mortality was observed in the two periods of the study, and that can be partially explained by prenatal diagnosis, which led to an in perinatal care.

\section{INFANTS WITH BIRTH WEIGHT LESS THAN THE $0.4^{\text {TH }}$ CENTILE HAVE HIGH RATES OF DISABILITY AND POOR GROWTH AT 2 YEARS}

R. Chaudhary ${ }^{1}$, V. Palanivel ${ }^{2}$, A. Curley ${ }^{1}$, A. Damore ${ }^{1}$, East Anglian VLBW project

${ }^{1} \mathrm{NICU},{ }^{2}$ Addenbrookes Hospital, Cambridge, UK

Background: Survival of very low birth weight (VLBW) infants has increased. Within this cohort infants born less than the $0.4^{\text {th }}$ centile are a high risk group. Studies of this subgroup have been small and have suggested these infants are at increased risk of long term neurodevelopmental problems.

Methods: Clinical and 2 year outcome data were collected on all VLBW infants $<0.4^{\text {th }}$ centile born between 1993 to 2002 from a regional database

Results: 128 infants were born below $0.4^{\text {th }}$ centile (median gestational age 34, range 24-39 weeks). $43 \%$ had some disability with $23 \%$ having moderate to severe disability. $3 \%$ had cerebral palsy (2 diplegia,1 hemiplegia, 1 quadriplegia). 11\% had motor impairment. 35\% had sensory impairment, $47 \%$ of these were moderate to severe. $56 \%$ required readmission within the first 2 years (median: 2, range: 1 to 9). $13 \%$ had three or more admissions. $58 \%$ were referred to one or more community services. Eleven different community services were involved in this. In terms of growth $16 \%$ of babies were still below the $0.4^{\text {th }}$ centile and $59 \%$ were below the $9^{\text {th }}$ centile at two years of age. Head circumferences were noted to be below the $9^{\text {th }}$ centile at 2 years in $72 \%$ babies.

Conclusion: Despite greater gestational age this cohort has higher rate of disability at 2 years $(23 \%)$ than the overall VLBW group (19\%). Many infants born below $0.4^{\text {th }}$ centile have long term health problems and significant health service requirements. Systemic and head growth remain poor at 2 years of age. 